\title{
The Anticonvulsant Enaminone E139 Attenuates Paclitaxel-Induced Neuropathic Pain in Rodents
}

\author{
Dhandapani Thangamani, ${ }^{1}$ Ivan Ogheneochuko Edafiogho, ${ }^{2}$ and Willias Masocha ${ }^{1}$ \\ ${ }^{1}$ Department of Pharmacology and Therapeutics, Faculty of Pharmacy, Kuwait University, P.O. Box 24923, 13110 Safat, Kuwait \\ ${ }^{2}$ Department of Pharmaceutical Sciences, School of Pharmacy, University of Saint Joseph, Hartford, CT 06103, USA \\ Correspondence should be addressed to Willias Masocha; masocha@hsc.edu.kw
}

Received 22 October 2013; Accepted 20 November 2013

Academic Editors: S. Caccia and T. Nagai

Copyright (c) 2013 Dhandapani Thangamani et al. This is an open access article distributed under the Creative Commons Attribution License, which permits unrestricted use, distribution, and reproduction in any medium, provided the original work is properly cited.

\begin{abstract}
The enaminone methyl 4-(4'-bromophenyl)aminocyclohex-3-en-6-methyl-2-oxo-1-oate (E139) has anticonvulsant activities. It has been reported to have a better safety profile than some anticonvulsant drugs. Since some anticonvulsant drugs are used in the management of neuropathic pain, we evaluated the effects of E139 in rodent models of acute pain and paclitaxelinduced neuropathic pain. The reaction latency to thermal stimuli (hot-plate test) of BALB/c mice was recorded before and after intraperitoneal treatment with paclitaxel $(2 \mathrm{mg} / \mathrm{kg}$, i.p. for 5 consecutive days), and after treatment with E139 (0.1-40 mg/kg), amitriptyline $(10 \mathrm{mg} / \mathrm{kg})$, and gabapentin $(10$ and $30 \mathrm{mg} / \mathrm{kg})$. Mechanical allodynia in paclitaxel-treated Sprague Dawley (SD) rats was measured using a dynamic plantar aesthesiometer before and after treatment with E139 (10 and $20 \mathrm{mg} / \mathrm{kg}$ ) or its vehicle for four consecutive days from day 7 after first administration of paclitaxel ( $16 \mathrm{mg} / \mathrm{kg}$ on two alternate days). Administration of E139 $(10-40 \mathrm{mg} / \mathrm{kg})$ produced antinociceptive activity against thermal nociception in naïve mice. Treatment with E139, amitriptyline, or gabapentin reduced paclitaxel-induced thermal hyperalgesia. E139 reduced paclitaxel-induced mechanical allodynia, with the effects lasting longer $(24 \mathrm{~h})$ after repetitive dosing. Our results indicate that E139 has antinociceptive activity and attenuates paclitaxel-induced neuropathic pain in rodents.
\end{abstract}

\section{Introduction}

Paclitaxel (taxol), a taxane with mitotic spindle inhibitory activity, is a key component of regimens used in the treatment of various solid tumors including ovarian, breast, and lung cancer. Its use, however, is negatively affected by the development of dose-limiting painful peripheral neuropathy [1]. Neurotoxicity is considered the major nonhematologic side effect of paclitaxel [2]. Paclitaxel causes acute pain syndrome, impairs sensory fibers, and produces peripheral neuropathy that present as a chronic painful neuropathic syndrome in some of the patients with symptoms that include hyperalgesia, allodynia, and spontaneous sensations such as burning, shooting, numbness, spasm, and prickling [3, 4].

Currently, there are no proven effective drugs for the prevention or treatment of paclitaxel-induced neuropathic pain (PINP) or chemotherapy-induced peripheral neuropathy $(\mathrm{CIPN})$ in general. Tricyclic antidepressants such as amitriptyline and anticonvulsants such as gabapentin have been used for symptomatic treatment of CIPN. Unfortunately, these drugs often have no significant benefit, provide only partial relief, or have dose limiting side effects $[5,6]$. Therefore, new alternative drugs are needed. Enaminones, which are enamines of $\beta$-dicarbonyl compounds, have been reported to have anticonvulsant effects in in vitro and in vivo models with minimal side effects [7-9]. The antinociceptive potential of enaminones has not yet been evaluated. The aim of this study was to evaluate the antinociceptive effects of the enaminone methyl 4 -( $4^{\prime}$-bromophenyl)aminocyclohex3-en-6-methyl-2-oxo-1-oate (E139) in naïve mice and in mice and rat models of PINP that manifest mechanical allodynia or thermal hyperalgesia $[10,11]$. E139 has been reported to suppress tetrodotoxin- (TTX-) sensitive sodium channels and enhance extracellular levels of GABA $[8,12]$. Sodium channels have been implicated in the pathogenesis of PINP [13] and the alteration of the GABAergic system plays 


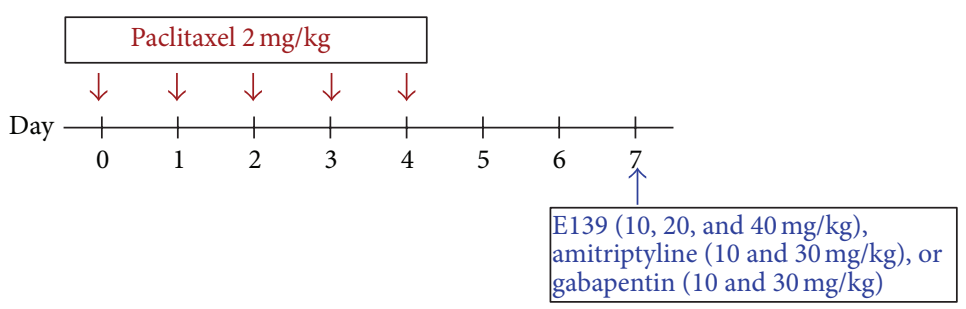

(a)

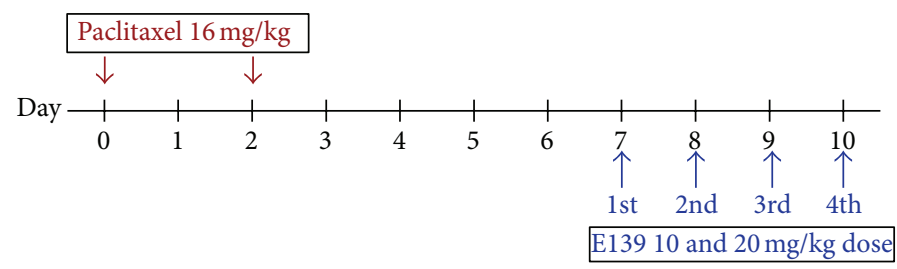

(b)

FIGURE 1: Drug administration schedule for (a) mice and (b) rats. The arrows indicate the days when the drugs were intraperitoneally administered.

a role in chronic pain syndromes [14]; thus, E139 might have antinociceptive effects against PINP.

\section{Materials and Methods}

2.1. Animals. The animals used in this study were female $\mathrm{BALB} / \mathrm{c}$ mice ( 8 to 12 weeks old; $20-30 \mathrm{~g}, n=176$ ) and male Sprague Dawley rats ( 8 to 12 weeks old; $200-300$ g, $n=$ 67) supplied by the Animal Resources Centre at the Health Sciences Center, Kuwait University, Kuwait. Animals were kept in temperature controlled $\left(24 \pm 1^{\circ} \mathrm{C}\right)$ rooms with food and water ad libitum. All experiments were performed during the same period of the day (8:00 AM to 4:00 PM) to exclude diurnal variations in pharmacological effects. The animals were handled in compliance with European Communities Council Directive 86/609 for the care of laboratory animals and ethical guidelines for research in experimental pain with conscious animals [15]. All procedures were approved by the Ethical Committee for the use of Laboratory Animals in Teaching and in Research, Health Sciences Centre, Kuwait University.

\subsection{Administration of Paclitaxel to Induce Neuropathic Pain.} Paclitaxel (Tocris, Bristol, UK) was dissolved in a solution made up of 50\% Cremophor EL and 50\% absolute ethanol to a concentration of $6 \mathrm{mg} / \mathrm{mL}$ and stored at $-20^{\circ} \mathrm{C}$, for a maximum of 14 days. For treatment of mice the $6 \mathrm{mg} / \mathrm{mL}$ paclitaxel solution was then diluted in normal saline $(\mathrm{NaCl}$ $0.9 \%$ ), to a final concentration of $0.2 \mathrm{mg} / \mathrm{mL}$ just before administration. The vehicle for paclitaxel was diluted at the time of injection with normal saline in the same proportion as the paclitaxel solution. Paclitaxel $2 \mathrm{mg} / \mathrm{kg}$ or its vehicle were administered to mice intraperitoneally (i.p.), in a volume of $10 \mathrm{~mL} / \mathrm{kg}$, once per day for 5 consecutive days; the cumulative dose of paclitaxel was $10 \mathrm{mg} / \mathrm{kg}$ (the paclitaxel administration schedule for mice is depicted in Figure 1(a), illustration adapted from Hidaka et al. [16]). This treatment regimen has been reported to produce painful neuropathy and thermal hyperalgesia in mice $[11,13]$. Paclitaxel $16 \mathrm{mg} / \mathrm{kg}$ or its vehicle, without dilution with $\mathrm{NaCl} 0.9 \%$, were administered to rats intraperitoneally (i.p.) as previously described [10], in a volume of $2.667 \mathrm{~mL} / \mathrm{kg}$, on two alternate days; the cumulative dose was $32 \mathrm{mg} / \mathrm{kg}$ (the paclitaxel administration schedule for rats is depicted in Figure 1(b)).

2.3. Drug Administration. E139 was synthesized in-house [7], dissolved in peanut oil, and administered i.p. to mice at a volume of $5 \mathrm{~mL} / \mathrm{kg}$ body mass and to rats at a volume of $2.5 \mathrm{~mL} / \mathrm{kg}$ body mass. E139 (0.1-40 mg/kg) was administered to naive mice and to paclitaxel treated mice at 7 days after first administration of paclitaxel, when mice had developed thermal hyperalgesia as previously described [11]. Amitriptyline (Sigma-Aldrich, St Louis, MO, USA; 10 and $30 \mathrm{mg} / \mathrm{kg}$ ) and gabapentin (Sigma-Aldrich, St Louis, MO, USA; 10 and $30 \mathrm{mg} / \mathrm{kg}$ ) were dissolved in normal saline and administered to paclitaxel treated mice at 7 days after first administration of paclitaxel. The E139, amitriptyline, and gabapentin administration schedule for mice is depicted in Figure 1(a). E139 (10 and $20 \mathrm{mg} / \mathrm{kg}$ ) was administered to rats for four consecutive days from day 7 after first administration of paclitaxel, when rats had developed mechanical allodynia (the E139 administration schedule for rats is depicted in Figure 1(b)).

2.4. Assessment of Thermal Nociception. Reaction latencies to hot-plate test were measured before (baseline latency), at day 7 after first injection of paclitaxel and at various times starting at 30 minutes after E139, amitriptyline, or gabapentin treatment. Briefly, mice were individually placed on a hot plate (Panlab SL, Barcelona, Spain) with the temperature adjusted to $55 \pm 1^{\circ} \mathrm{C}$. The time to the first sign of nociception, paw licking, flinching, or jump response to avoid the heat was recorded and the animal immediately was removed from the hot plate. A cut-off period of 20 seconds was maintained 


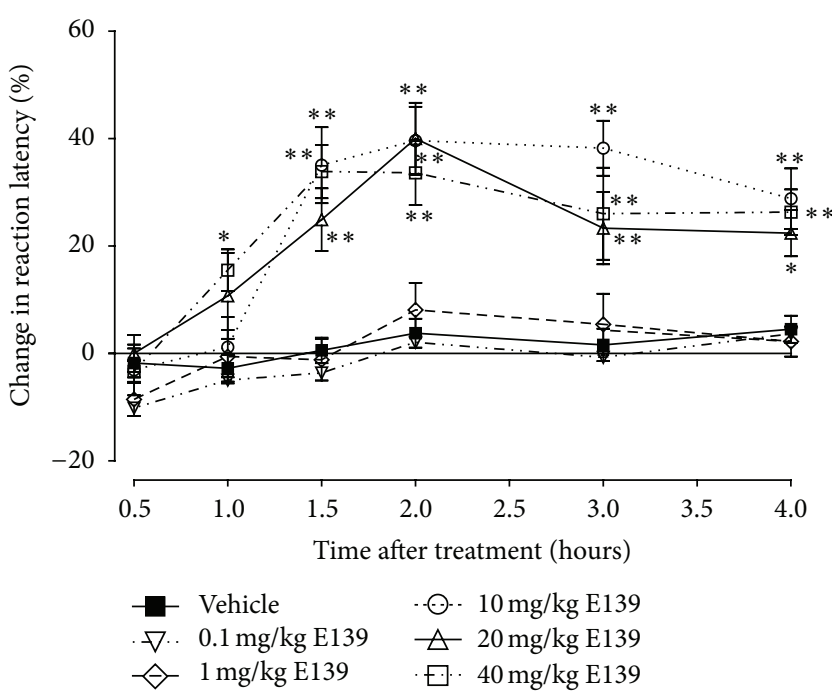

FIGURE 2: Time course of the percentage change in reaction latency time for various doses of E139 $(0.1-40 \mathrm{mg} / \mathrm{kg})$ in a hot-plate test in naïve $\mathrm{BALB} / \mathrm{c}$ mice. Each point represents the mean \pm S.E.M of values obtained from 10 animals. ${ }^{*} P<0.05$ and ${ }^{* *} P<0.01$ compared to drug vehicle at the same time point after treatment (two-way repeated measures ANOVA followed by Bonferroni test).

to avoid damage to the paws. Percent change in reaction latency was calculated as follows: [(response latency after drug treatment-pretreatment baseline latency)/pretreatment baseline latency] $\times 100$.

2.5. Assessment of Mechanical Allodynia. Mechanical allodynia in rats was measured using the dynamic plantar aesthesiometer (Ugo Basile, Italy), as previously described [10, 17] and following the procedures described by the manufacturer. Briefly, rats were left to habituate for about 15 minutes inside plastic enclosures on top of a perforated platform before starting a microprocessor which was programmed to automatically lift a metal filament that exerted a linearly increasing force ( $2.5 \mathrm{~g} / \mathrm{s}$ with cut-off time of $20 \mathrm{~s})$ on the hind paw. A stop signal was automatically attained, either when the animal removed the paw or at the cut-off force of $50 \mathrm{~g}$. Withdrawal thresholds in response to the mechanical stimulus was automatically recorded in grams. The hind paws were tested at least 3 times with a 3-5 minute interval. Percent change in withdrawal force was calculated as follows: [(withdrawal force after drug treatment-pretreatment baseline withdrawal force)/pretreatment baseline withdrawal force] $\times 100$.

2.6. Statistical Analyses. Statistical analyses were performed using Student's $t$-test, one-way analysis of variance (ANOVA) followed by Dunnett's multiple comparison test, Grubbs' test, Kruskal-Wallis test, or two-way repeated measures ANOVA followed by Bonferroni posttests. The differences were considered significant at $P<0.05$.

\section{Results}

3.1. Effects of Treatment with E139 in a Hot-Plate Test in Nä̈ve $B A L B / c$ Mice. The intraperitoneal administration of vehicle or lower doses of E139 $(0.1$ and $1 \mathrm{mg} / \mathrm{kg})$ did not change the reaction latency to thermal stimulation $(P>0.05)$, whereas higher doses $(10,20$, and $40 \mathrm{mg} / \mathrm{kg})$ produced significant percentage increase in reaction latency compared to vehicletreated mice $(P<0.05$; Figure 2$)$. There was a significant interaction between treatment and time after treatment for E139 doses of $10 \mathrm{mg} / \mathrm{kg}\left(F_{5,90}=12.43, P<0.0001\right), 20 \mathrm{mg} / \mathrm{kg}$ $\left(F_{5,90}=4.72, P=0.0007\right)$, and $40 \mathrm{mg} / \mathrm{kg}\left(F_{5,90}=6.40\right.$, $P<0.0001)$. The effect of E139 was time dependent; from the time of administration it rose to a peak between 1.5 and $3 \mathrm{~h}$ and was still significantly high at $4 \mathrm{~h}$.

3.2. Effects of E139, Amitriptyline, and Gabapentin on Paclitaxel-Induced Thermal Hyperalgesia. Paclitaxel produced a significant reduction in response latency time to thermal stimuli (thermal hyperalgesia) on day 7 after first drug administration compared to the baseline latency (pretreatment values) and vehicle-only-treated animals in the hotplate test $(P<0.01$; Figure 3(a)), as previously described [11].

The intraperitoneal administration of E139 $(10,20$, and $40 \mathrm{mg} / \mathrm{kg}$ ) produced significant percentage increase in reaction latency in mice with paclitaxel-induced thermal hyperalgesia compared to vehicle-treated animals $(P<0.05$, Figure 3(b)). There was a significant interaction between treatment and time after treatment for E139 doses of $10 \mathrm{mg} / \mathrm{kg}\left(F_{5,110}=5.65, P=0.0001\right)$ and $20 \mathrm{mg} / \mathrm{kg}$ $\left(F_{5,110}=2.30, P=0.0494\right)$ but not $40 \mathrm{mg} / \mathrm{kg}\left(F_{5,110}=1.96\right.$, $P=0.0909)$. The effect of E139 was time dependent; from the time of administration it produced significant effects from $2 \mathrm{~h}$ onwards.

The intraperitoneal administration of amitriptyline at a dose of $10 \mathrm{mg} / \mathrm{kg}$, which has been shown to reduce thermal hyperalgesia in another model of neuropathic pain [18], also produced significant percentage increase in reaction latency in mice with paclitaxel-induced thermal hyperalgesia compared to vehicle-treated animals $(P<0.05$, Figure 4$)$. There was a significant interaction between treatment and time after treatment for amitriptyline $10 \mathrm{mg} / \mathrm{kg}\left(F_{5,130}=\right.$ $3.45, P=0.0058)$. The effect of amitriptyline was also time dependent, producing significant effects earlier than E139 at $1.5 \mathrm{~h}$ after administration but was also short lived, having no significant effects $2 \mathrm{~h}$ after administration. The peak effect of amitriptyline $10 \mathrm{mg} / \mathrm{kg}$ at $1.5 \mathrm{~h}$ was $37.7 \pm 8.9 \%$ increase in reaction latency, which was earlier than but similar in magnitude $(P>0.05)$ to that of E139 $10 \mathrm{mg} / \mathrm{kg}$ (at $3 \mathrm{~h}$ and $35.0 \pm 6.1 \%$ increase in reaction latency). A higher dose of amitriptyline $(30 \mathrm{mg} / \mathrm{kg})$ caused sedation and thus was not evaluated in the hot-plate test.

The intraperitoneal administration of gabapentin, which has been shown to reduce paclitaxel-induced thermal hyperalgesia [19], 10 and $30 \mathrm{mg} / \mathrm{kg}$ also produced significant percentage increase in reaction latency in mice with paclitaxelinduced thermal hyperalgesia compared to vehicle-treated animals $(P<0.05$, Figure 4$)$. There was a significant interaction between treatment and time after treatment for 


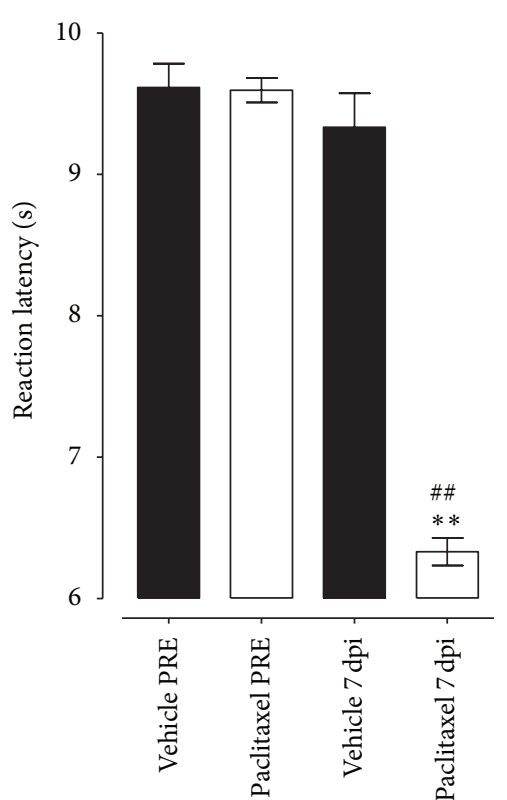

(a)

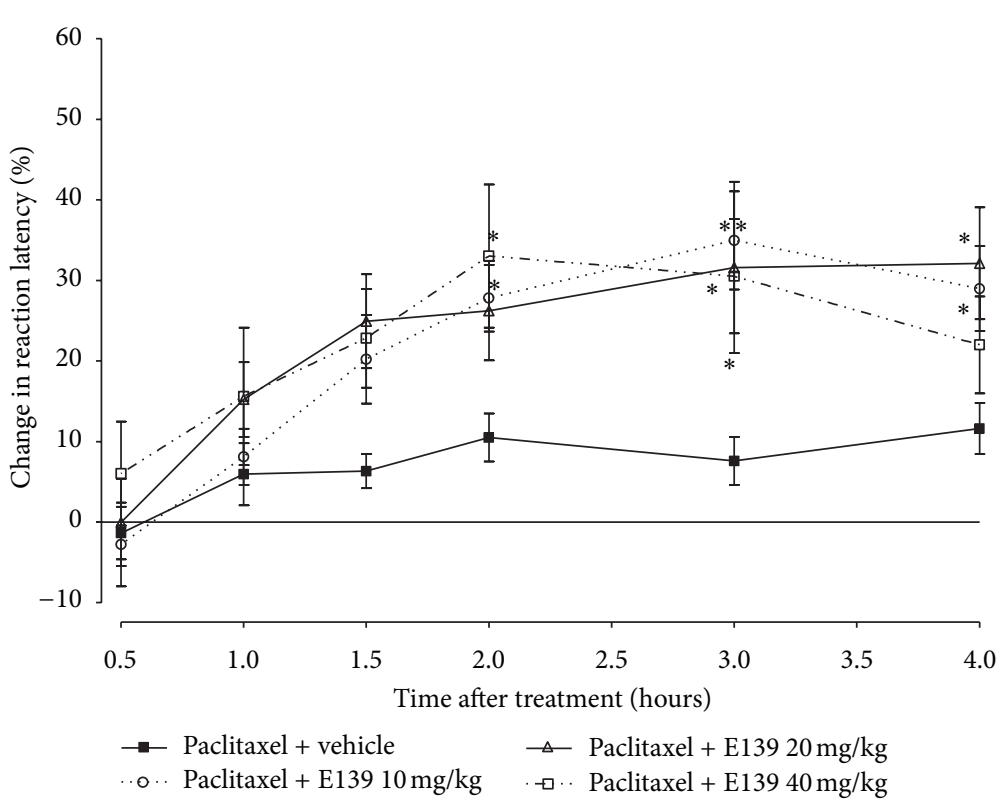

(b)

FIGURE 3: Effect of treatment with E139 on BALB/c mice with paclitaxel-induced thermal hyperalgesia in a hot-plate test. (a) Thermal hyperalgesia in BALB/c mice at day 7 after first inoculation of paclitaxel (administered at $2 \mathrm{mg} / \mathrm{kg}$, i.p. for 5 consecutive days). Each point represents the mean \pm S.E.M of values obtained from 22 vehicle-treated and 94 paclitaxel-treated animals. ${ }^{* *} P<0.01$ compared to drug vehicle at the same day after treatment and ${ }^{\# \#} P<0.01$ compared to pretreatment (PRE) values (Student's $t$-test). (b) Percentage change in reaction latency times from baseline values (taken at day 7 after first administration of paclitaxel) at different times after treatment with E139 $(10-40 \mathrm{mg} / \mathrm{kg})$ or its vehicle in hot-plate test. Each bar represents the mean \pm S.E.M of values obtained from 12 animals. ${ }^{* *} P<0.01$ compared to drug vehicle at the same time point after treatment (two-way repeated measures ANOVA followed by Bonferroni test).

gabapentin doses of $10 \mathrm{mg} / \mathrm{kg}\left(F_{5,110}=3.72, P=0.0038\right)$ and $30 \mathrm{mg} / \mathrm{kg}\left(F_{5,110}=9.29, P<0.0001\right)$. The effect of gabapentin was also time dependent, producing significant effects earlier than E139 at $0.5 \mathrm{~h}$ after administration but was also short lived, having no significant effects $1.5 \mathrm{~h}$ after administration. The peak effects of gabapentin 10 and $30 \mathrm{mg} / \mathrm{kg}$ at $1 \mathrm{~h}$ were $37.7 \pm 9.3 \%$ and $41.3 \pm 7.9 \%$ increase in reaction latency, respectively, which were earlier than but similar in magnitude $(P>0.05)$ to that of E139 $10 \mathrm{mg} / \mathrm{kg}$ (at $3 \mathrm{~h}$ and $35.0 \pm 6.1 \%$ increase in reaction latency).

\subsection{Effects of E139 on Paclitaxel-Induced Mechanical Allody-} nia. Paclitaxel produced a significant reduction in response withdrawal threshold to mechanical stimuli (mechanical allodynia), as previously described [10], from 7 to 17 days after first drug administration compared to the baseline latency and vehicle-only-treated animals measured using the dynamic plantar aesthesiometer $(P<0.05$; Figure 5(a)). There was a significant interaction between treatment with paclitaxel and time after treatment $\left(F_{7,128}=11.08, P<\right.$ $0.0001)$. The nadir of the reduction of the withdrawal threshold was on day 9, where paclitaxel treated rats had a withdrawal threshold of $11.6 \pm 1.4 \mathrm{~g}$ compared to $35.0 \pm$ $2.4 \mathrm{~g}$ before paclitaxel treatment, almost $70 \%$ reduction in withdrawal threshold.
Rats with paclitaxel induced mechanical allodynia were treated with E139 (10 and $20 \mathrm{mg} / \mathrm{kg}$ ) or its vehicle daily for four consecutive days from day 7 after first administration of paclitaxel. One of the rats with paclitaxel-induced mechanical allodynia treated with vehicle produced values which were significant outliers $(P<0.05$, Grubbs' test performed using http:/graphpad.com/quickcalcs/Grubbsl.cfm). The values obtained from this animal were presented together with those obtained from the rest of the other animals in this group as median values with interquartile range and the data in this set was analyzed using a nonparametric statistical test, KruskalWallis test.

The intraperitoneal administration of E139 $10 \mathrm{mg} / \mathrm{kg}$ significantly increased the withdrawal threshold in rats with paclitaxel-induced mechanical allodynia compared to vehicle-treated animals only for the first two doses and at $2 \mathrm{~h}(P<0.05)$ but not at $24 \mathrm{~h}$ after drug administration $(P>0.05$; Figure 5(b)). On the other hand the intraperitoneal administration of a higher dose of E139 $20 \mathrm{mg} / \mathrm{kg}$ significantly increased the withdrawal threshold in rats with paclitaxelinduced mechanical allodynia compared to vehicle-treated animals at $2 \mathrm{~h}(P<0.05)$ after drug administration $(P<$ 0.05; Figure 5(b)) throughout the duration of the treatment (four doses). The effects of E139 $20 \mathrm{mg} / \mathrm{kg}$ lasted for $24 \mathrm{~h}$ $(P<0.05)$ starting from the third administration of the drug. 


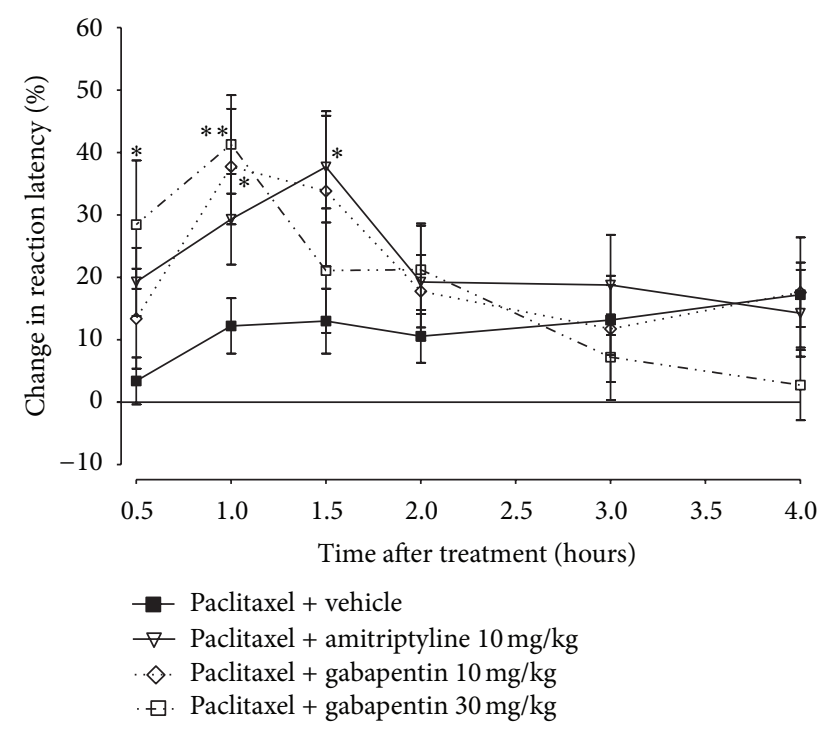

FIGURE 4: Effect of treatment with amitriptyline and gabapentin on BALB/c mice with paclitaxel-induced thermal hyperalgesia in a hot-plate test. Percentage change in reaction latency times from baseline values (taken at day 7 after first administration of paclitaxel) at different times after treatment with amitriptyline $(10 \mathrm{mg} / \mathrm{kg})$, gabapentin $(10$ and $30 \mathrm{mg} / \mathrm{kg}$ ), or their vehicle in a hot-plate test. Each bar represents the mean \pm S.E.M of values obtained from 8-16 animals. ${ }^{*} P<0.05$ compared to drug vehicle at the same time point after treatment (two-way repeated measures ANOVA followed by Bonferroni test).

\section{Discussion}

This study shows for the first time that an anticonvulsant enaminone E139 has antinociceptive activities in naïve mice and attenuates paclitaxel-induced thermal hyperalgesia and mechanical allodynia in rodents.

E139 has been shown to have anticonvulsant activities in vivo in animals with minimal side effects. It was found to have a median toxic dose $\left(\mathrm{TD}_{50}\right)$ of $270 \mathrm{mg} / \mathrm{kg}$ in rats [20], which was far above the highest dose we used, $40 \mathrm{mg} / \mathrm{kg}$, and found to have antinociceptive activities. E139 did not display any motor impairment in mice at a dose of $50 \mathrm{mg} / \mathrm{kg}$ [20]. In rats E139 neither produced neurotoxicity at a dose of $110 \mathrm{mg} / \mathrm{kg}$ nor did it elicit ataxia [20]. On the other hand, amitriptyline an antidepressant drug which has been used for symptomatic management of CIPN $[5,21]$ had sedative effects in paclitaxeltreated BALB/c mice at a dose of $30 \mathrm{mg} / \mathrm{kg}$, the same dose has been observed to induce somnolence in rats [22]; thus we had to limit the dose we evaluated for antinociceptive activity to $10 \mathrm{mg} / \mathrm{kg}$. Amitriptyline is known to have dose-limiting sedative effects $[23,24]$ and has also been reported to cause ataxia [25]. Somnolence, dizziness, and ataxia are also doselimiting side effects of gabapentin [25-27] an anticonvulsant drug that has also been used for symptomatic management of CIPN $[21,28]$.

E139 produced antinociceptive effects against thermal nociception in naïve mice similar to what has been observed with amitriptyline or gabapentin [29-32]. We observed antinociceptive effects of E139, amitriptyline, and gabapentin in mice with paclitaxel-induced thermal hyperalgesia. We did not find studies describing the effects of amitriptyline against paclitaxel-induced thermal hyperalgesia, but the drug was found to have antinociceptive effects in other models of neuropathic pain $[18,33]$. On the other hand, gabapentin has been shown to have antinociceptive effects in mice with paclitaxel-induced thermal hyperalgesia [19].

Mechanical allodynia is a well-known feature in rats treated with paclitaxel $[34,35]$ and the effects of both amitriptyline and gabapentin have been studied on symptomatic relief of established paclitaxel-induced mechanical allodynia [36, 37]. E139 attenuated paclitaxel-induced mechanical allodynia from the first dose, however, repeated dosing was necessary for the effects of the drug to be long lasting (i.e., up to $24 \mathrm{~h}$ after treatment). This pattern to some extent is similar to what has been observed with both gabapentin and amitriptyline $[36,37]$. However, the immediate effects of E139 were observed earlier than either compound; that is, the first dose of E139 had some antiallodynic effect whilst amitriptyline and gabapentin did not $[36,37]$. One of the differences between these studies was that we examined the effects of E139 at 2 and $24 \mathrm{~h}$, whereas Xiao et al. examined the effects of amitriptyline and gabapentin at 1 and $24 \mathrm{~h}[36,37]$. E139 and amitriptyline's antiallodynic effects lasted up to $24 \mathrm{~h}$ after repetitive dosing whereas that of gabapentin did not $[36,37]$.

E139 has been reported to block TTX-sensitive sodium currents and enhance extracellular levels of GABA possibly via activation of $\alpha 2$-adrenoceptors in in vitro models of epilepsy [8, 12, 38, 39]. These activities of E139 are possibly responsible for its antinociceptive effects in rodent models of neuropathic pain. Systemic administration of low doses of TTX has been shown to have antinociceptive/antiallodynic activity in mice with paclitaxel-induced thermal hyperalgesia and mechanical allodynia [13]. Amitriptyline blocks sodium channels [40-42] and this has been suggested to be one of its possible mechanisms of activity against paclitaxel-induced neuropathic pain [37]. The antinociceptive effects of amitriptyline have also been attributed to its action on $\alpha 2$-adrenoceptors [43] and this and its effects on other $\alpha$-adrenoceptors are possibly responsible for its effects against neuropathic pain, including that induced by paclitaxel $[37,44,45]$. All these are in addition to its principal effects as a serotonin and noradrenaline reuptake inhibitor. Activation of GABA receptors using baclofen has also been shown to have antiallodynic activities in rats with paclitaxel-induced mechanical allodynia but not as consistently as amitriptyline [37]. Gabapentin, an anticonvulsant drug which acts via binding to $\alpha 2 \delta-1$ subunit containing voltage-gated calcium channels also has antinociceptive/antiallodynic effects in rodents with paclitaxel-induced neuropathic pain $[19,36,37]$. Taking into consideration our current findings and literature sources, the activities of E139 against neuropathic pain and possibly the mechanism of actions are more similar to that of amitriptyline than gabapentin. However, E139 is devoid of the sedative effect of amitriptyline. 


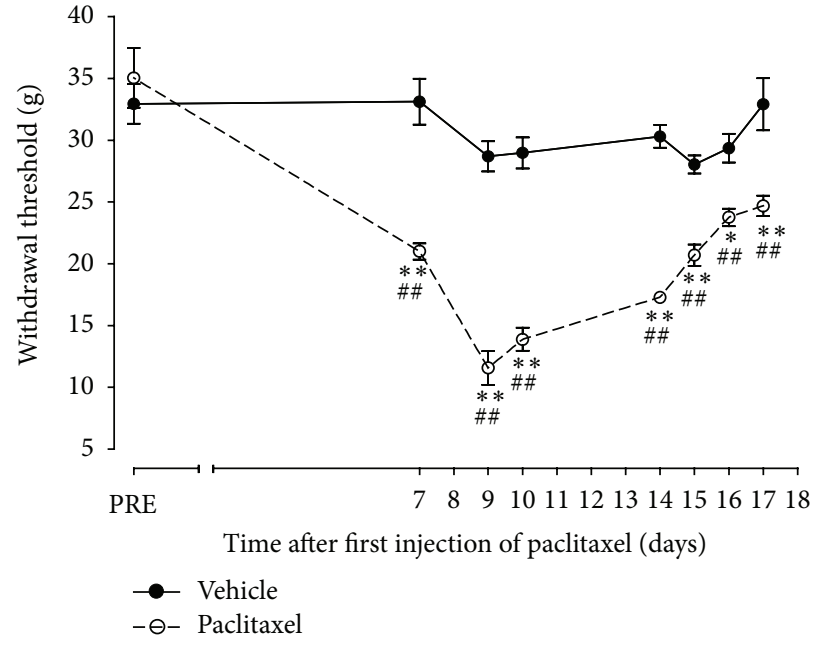

(a)

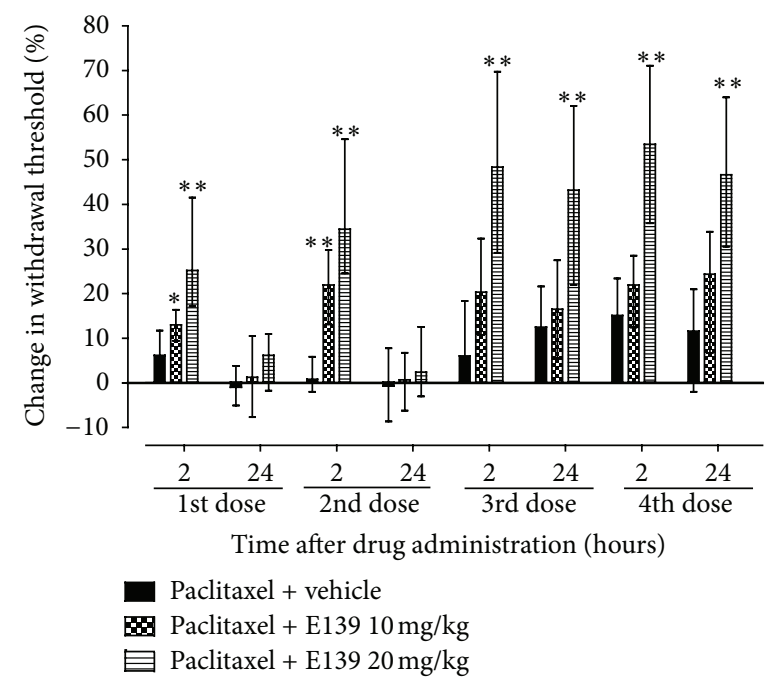

(b)

FIGURE 5: Effect of treatment with E139 on paclitaxel-induced mechanical allodynia in Sprague Dawley rats. (a) Time course of the withdrawal threshold to the dynamic plantar aesthesiometer after administration of paclitaxel $16 \mathrm{mg} / \mathrm{kg}$ or its vehicle on two alternate days. Each point represents the mean \pm S.E.M of values obtained from 9 animals. ${ }^{*} P<0.05$ and ${ }^{* *} P<0.01$ compared to drug vehicle at the same day after treatment (two-way repeated measures ANOVA followed by Bonferroni test) and ${ }^{\# \# ~} P<0.01$ compared to pretreatment (PRE) values (oneway ANOVA followed by Dunnett's multiple comparison test). (b) Percentage change in withdrawal threshold from baseline values (taken at day 7 after first administration of paclitaxel) at 2 and $24 \mathrm{~h}$ after each treatment with E139 (10 and $20 \mathrm{mg} / \mathrm{kg})$ or its vehicle using a dynamic plantar aesthesiometer. E139 was administered in 4 daily doses. Each bar represents the median values with interquartile range of values obtained from 16 to 17 animals. ${ }^{*} P<0.05$ and ${ }^{* *} P<0.01$ compared to drug vehicle at the same time point after treatment (Kruskal-Wallis test).

\section{Conclusions}

In conclusion the data obtained in this study show that the anticonvulsant enaminone E139 has antinociceptive activity, and attenuates paclitaxel-induced neuropathic pain. The antiallodynic activities of E139 are longer lasting after repetitive treatment; thus, repetitive dosing of E139 has potential therapeutic benefits in the management of paclitaxel-induced neuropathic pain.

\section{Conflict of Interests}

The authors declare that they have no conflict of interests.

\section{Authors' Contribution}

All authors contributed markedly to the paper, discussed the results, and commented on the paper. Dhandapani Thangamani participated in the acquisition and analysis of data; Ivan Ogheneochuko Edafiogho participated in the conception and design of the study and synthesis of E139; Willias Masocha participated in the conception and design of the study, acquisition and analysis of data, statistical analysis, project supervision, and drafting and preparation of the paper. All authors read and approved the final manuscript.

\section{Acknowledgments}

This study was supported by Grant PT01/09 from Kuwait University Research Sector. The authors are grateful to Professor Samuel Kombian for his support to this study and valuable comments on this paper. They are thankful to Dr. Subramanian S. Parvathy and Ms Princy Susan Geevarghese Mathew for their technical assistance and to the staff from the Animal Resources Centre, HSC, Kuwait University, for their support.

\section{References}

[1] S. Wolf, D. Barton, L. Kottschade, A. Grothey, and C. Loprinzi, "Chemotherapy-induced peripheral neuropathy: prevention and treatment strategies," European Journal of Cancer, vol. 44, no. 11, pp. 1507-1515, 2008.

[2] A. Bhagra and R. D. Rao, "Chemotheraphy-induced neuropathy," Current Oncology Reports, vol. 9, no. 4, pp. 290-299, 2007.

[3] F. H. Hausheer, R. L. Schilsky, S. Bain, E. J. Berghorn, and F. Lieberman, "Diagnosis, management, and evaluation of chemotherapy-induced peripheral neuropathy," Seminars in Oncology, vol. 33, no. 1, pp. 15-49, 2006.

[4] B. N. Reeves, S. R. Dakhil, J. A. Sloan et al., "Further data supporting that paclitaxel-associated acute pain syndrome is associated with development of peripheral neuropathy: North 
Central Cancer Treatment Group trial N08C1," Cancer, vol. 118, no. 20, pp. 5171-5178, 2012.

[5] A.-L. Kautio, M. Haanpää, T. Saarto, and E. Kalso, "Amitriptyline in the treatment of chemotherapy-induced neuropathic symptoms," Journal of Pain and Symptom Management, vol. 35, no. 1, pp. 31-39, 2008.

[6] R. D. Rao, J. C. Michalak, J. A. Sloan et al., "Efficacy of gabapentin in the management of chemotherapy-induced peripheral neuropathy: a phase 3 randomized, double-blind, placebo-controlled, crossover trial (N00C3)," Cancer, vol. 110, no. 9, pp. 2110-2118, 2007.

[7] I. O. Edafiogho, C. N. Hinko, H. Chang et al., "Synthesis and anticonvulsant activity of enaminones," Journal of Medicinal Chemistry, vol. 35, no. 15, pp. 2798-2805, 1992.

[8] S. B. Kombian, I. O. Edafiogho, and K. V. V. Ananthalakshmi, "Anticonvulsant enaminones depress excitatory synaptic transmission in the rat brain by enhancing extracellular GABA levels," British Journal of Pharmacology, vol. 145, no. 7, pp. 945953, 2005.

[9] D. Mulzac and K. R. Scott, "Profile of anticonvulsant activity and minimal toxicity of methyl 4 -[(p-chlorophenyl)amino]6-methyl-2-oxo-cyclohex-3-en-1-oate and some prototype antiepileptic drugs in mice and rats," Epilepsia, vol. 34, no. 6, pp. 1141-1146, 1993.

[10] K. Nishida, S. Kuchiiwa, S. Oiso et al., "Up-regulation of matrix metalloproteinase-3 in the dorsal root ganglion of rats with paclitaxel-induced neuropathy," Cancer Science, vol. 99, no. 8, pp. 1618-1625, 2008.

[11] S. S. Parvathy and W. Masocha, "Matrix metalloproteinase inhibitor COL-3 prevents the development of paclitaxelinduced hyperalgesia in mice," Medical Principles and Practice, vol. 22, pp. 35-41, 2013.

[12] K. V. Ananthalakshmi, I. O. Edafiogho, and S. B. Kombian, "Concentration-dependent effects of anticonvulsant enaminone methyl 4-(4'-bromophenyl)aminocyclohex-3-en-6methyl-2-oxo-1-oate on neuronal excitability in vitro," Neuroscience, vol. 141, no. 1, pp. 345-356, 2006.

[13] F. R. Nieto, J. M. Entrena, C. M. Cendán, E. D. Pozo, J. M. Vela, and J. M. Baeyens, "Tetrodotoxin inhibits the development and expression of neuropathic pain induced by paclitaxel in mice," Pain, vol. 137, no. 3, pp. 520-531, 2008.

[14] H. U. Zeilhofer, H. Möhler, and A. di Lio, "GABAergic analgesia: new insights from mutant mice and subtype-selective agonists," Trends in Pharmacological Sciences, vol. 30, no. 8, pp. 397-402, 2009.

[15] M. Zimmermann, "Ethical guidelines for investigations of experimental pain in conscious animals," Pain, vol. 16, no. 2, pp. 109-110, 1983.

[16] T. Hidaka, T. Shima, K. Nagira et al., "Herbal medicine Shakuyaku-kanzo-to reduces paclitaxel-induced painful peripheral neuropathy in mice," European Journal of Pain, vol. 13, no. 1, pp. 22-27, 2009.

[17] R. Nirogi, V. Goura, D. Shanmuganathan, P. Jayarajan, and R. Abraham, "Comparison of manual and automated filaments for evaluation of neuropathic pain behavior in rats," Journal of Pharmacological and Toxicological Methods, vol. 66, pp. 8-13, 2012.

[18] J.-S. Walczak, V. Pichette, F. Leblond, K. Desbiens, and P. Beaulieu, "Characterization of chronic constriction of the saphenous nerve, a model of neuropathic pain in mice showing rapid molecular and electrophysiological changes," Journal of Neuroscience Research, vol. 83, no. 7, pp. 1310-1322, 2006.
[19] M. Matsumoto, M. Inoue, A. Hald, W. Xie, and H. Ueda, "Inhibition of paclitaxel-induced A-fiber hypersensitization by gabapentin," Journal of Pharmacology and Experimental Therapeutics, vol. 318, no. 2, pp. 735-740, 2006.

[20] K. R. Scott, I. O. Edafiogho, E. L. Richardson et al., "Synthesis and anticonvulsant activity of enaminones. 2. Further structureactivity correlations," Journal of Medicinal Chemistry, vol. 36, no. 14, pp. 1947-1955, 1993.

[21] A. A. Argyriou, M. Koltzenburg, P. Polychronopoulos, S. Papapetropoulos, and H. P. Kalofonos, "Peripheral nerve damage associated with administration of taxanes in patients with cancer," Critical Reviews in Oncology/Hematology, vol. 66, no. 3, pp. 218-228, 2008.

[22] Y. Takeda, T. Ishida, R. Tsutsui et al., "Studies on somnolence in the daytime caused by drugs used for neuropathic pain," Journal of Pharmacological Sciences, vol. 107, no. 3, pp. 246-250, 2008.

[23] C. Dallocchio, C. Buffa, P. Mazzarello, and S. Chiroli, "Gabapentin versus amitriptyline in painful diabetic neuropathy: an open-label pilot study," Journal of Pain and Symptom Management, vol. 20, no. 4, pp. 280-285, 2000.

[24] S. O. Ogren, J. M. Cott, and H. Hall, "Sedative/anxiolytic effects of antidepressants in animals," Acta Psychiatrica Scandinavica, vol. 290, pp. 277-288, 1981.

[25] C. M. Morello, S. G. Leckband, C. P. Stoner, D. F. Moorhouse, and G. A. Sahagian, "Randomized double-blind study comparing the efficacy of gabapentin with amitriptyline on diabetic peripheral neuropathy pain," Archives of Internal Medicine, vol. 159, no. 16, pp. 1931-1937, 1999.

[26] I. Gilron, J. M. Bailey, D. Tu, R. R. Holden, A. C. Jackson, and R. L. Houlden, "Nortriptyline and gabapentin, alone and in combination for neuropathic pain: a double-blind, randomised controlled crossover trial," The Lancet, vol. 374, no. 9697, pp. 1252-1261, 2009.

[27] M. Rowbotham, N. Harden, B. Stacey, P. Bernstein, and L. Magnus-Miller, "Gabapentin for the treatment of postherpetic neuralgia: a randomized controlled trial," Journal of the American Medical Association, vol. 280, no. 21, pp. 1837-1842, 1998.

[28] N. Tsavaris, P. Kopterides, C. Kosmas et al., "Gabapentin monotherapy for the treatment of chemotherapy-induced neuropathic pain: a pilot study," Pain Medicine, vol. 9, no. 8, pp. 1209-1216, 2008.

[29] D. Ardid and G. Guilbaud, "Antinociceptive effects of acute and "chronic" injections of tricyclic antidepressant drugs in a new model of mononeuropathy in rats," Pain, vol. 49, no. 2, pp. 279$287,1992$.

[30] N. Galeotti, C. Ghelardini, S. Capaccioli, A. Quattrone, A. Nicolin, and A. Bartolini, "Blockade of clomipramine and amitriptyline analgesia by an antisense oligonucleotide to mKv1.1, a mouse Shaker-like $\mathrm{K}^{+}$channel," European Journal of Pharmacology, vol. 330, no. 1, pp. 15-25, 1997.

[31] F. S. Kilic, B. Sirmagul, E. Yildirim, S. Oner, and K. Erol, "Antinociceptive effects of gabapentin \& its mechanism of action in experimental animal studies," Indian Journal of Medical Research, vol. 135, pp. 630-635, 2012.

[32] K. R. Paudel, B. P. Das, G. P. Rauniar, H. Sangraula, S. Deo, and S. K. Bhattacharya, "Antinociceptive effect of amitriptyline in mice of acute pain models," Indian Journal of Experimental Biology, vol. 45, no. 6, pp. 529-531, 2007.

[33] D. Mahmood, M. Akhtar, D. Vohora, and R. Khanam, "Comparison of antinociceptive and antidiabetic effects of sertraline and amitriptyline on streptozotocin-induced diabetic rats," Human and Experimental Toxicology, vol. 29, no. 10, pp. 881-886, 2010. 
[34] C. M. Peters, J. M. Jimenez-Andrade, M. A. Kuskowski, J. R. Ghilardi, and P. W. Mantyh, "An evolving cellular pathology occurs in dorsal root ganglia, peripheral nerve and spinal cord following intravenous administration of paclitaxel in the rat," Brain Research, vol. 1168, no. 1, pp. 46-59, 2007.

[35] R. C. Polomano and G. J. Bennett, "Chemotherapy-evoked painful peripheral neuropathy," Pain Medicine, vol. 2, no. 1, pp. 8-14, 2001.

[36] W. Xiao, A. Boroujerdi, G. J. Bennett, and Z. D. Luo, "Chemotherapy-evoked painful peripheral neuropathy: analgesic effects of gabapentin and effects on expression of the alpha-2-delta type-1 calcium channel subunit," Neuroscience, vol. 144 , no. 2, pp. 714-720, 2007.

[37] W. Xiao, L. Naso, and G. J. Bennett, "Experimental studies of potential analgesics for the treatment of chemotherapy-evoked painful peripheral neuropathies," Pain Medicine, vol. 9, no. 5, pp. 505-517, 2008.

[38] K. V. V. Ananthalakshmi, I. O. Edafiogho, and S. B. Kombian, "Anticonvulsant enaminone E139 suppresses epileptiform activity in rat hippocampal slices," Epilepsy Research, vol. 76, no. 2-3, pp. 85-92, 2007.

[39] S. B. Kombian, K. V. V. Ananthalakshmi, and I. O. Edafiogho, "Enaminones and norepinephrine employ convergent mechanisms to depress excitatory synaptic transmission in the rat nucleus accumbens in vitro," European Journal of Neuroscience, vol. 24, no. 10, pp. 2781-2788, 2006.

[40] I. E. Dick, R. M. Brochu, Y. Purohit, G. J. Kaczorowski, W. J. Martin, and B. T. Priest, "Sodium channel blockade may contribute to the analgesic efficacy of antidepressants," Journal of Pain, vol. 8, no. 4, pp. 315-324, 2007.

[41] Y.-K. Hur, I.-S. Choi, J.-H. Cho et al., "Effects of carbamazepine and amitriptyline on tetrodotoxin-resistant $\mathrm{Na}^{+}$channels in immature rat trigeminal ganglion neurons," Archives of Pharmacal Research, vol. 31, no. 2, pp. 178-182, 2008.

[42] J.-H. Song, S.-S. Ham, Y.-K. Shin, and C.-S. Lee, "Amitriptyline modulation of $\mathrm{Na}^{+}$channels in rat dorsal root ganglion neurons," European Journal of Pharmacology, vol. 401, no. 3, pp. 297-305, 2000.

[43] C. Ghelardini, N. Galeotti, and A. Bartolini, "Antinociception induced by amitriptyline and imipramine is mediated by $\alpha(2 \mathrm{~A})$ adrenoceptors," Japanese Journal of Pharmacology, vol. 82, no. 2, pp. 130-137, 2000.

[44] M. J. Esser and J. Sawynok, "Caffeine blockade of the thermal antihyperalgesic effect of acute amitriptyline in a rat model of neuropathic pain," European Journal of Pharmacology, vol. 399, no. 2-3, pp. 131-139, 2000.

[45] A. Ulugol, H. C. Karadag, M. Tamer, Z. Firat, A. Aslantas, and I. Dokmeci, "Involvement of adenosine in the anti-allodynic effect of amitriptyline in streptozotocin-induced diabetic rats," Neuroscience Letters, vol. 328, no. 2, pp. 129-132, 2002. 

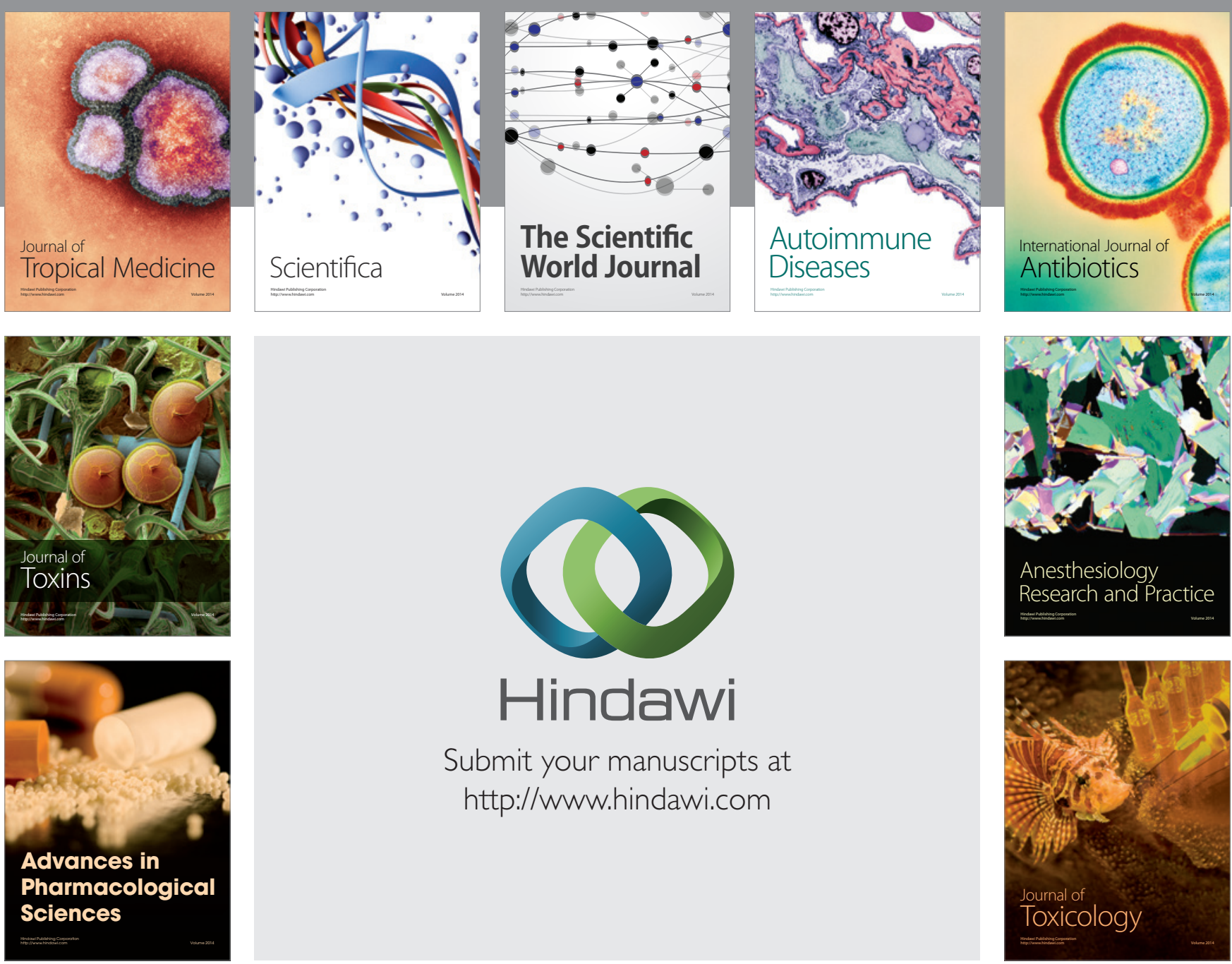

\section{Hindawi}

Submit your manuscripts at

http://www.hindawi.com
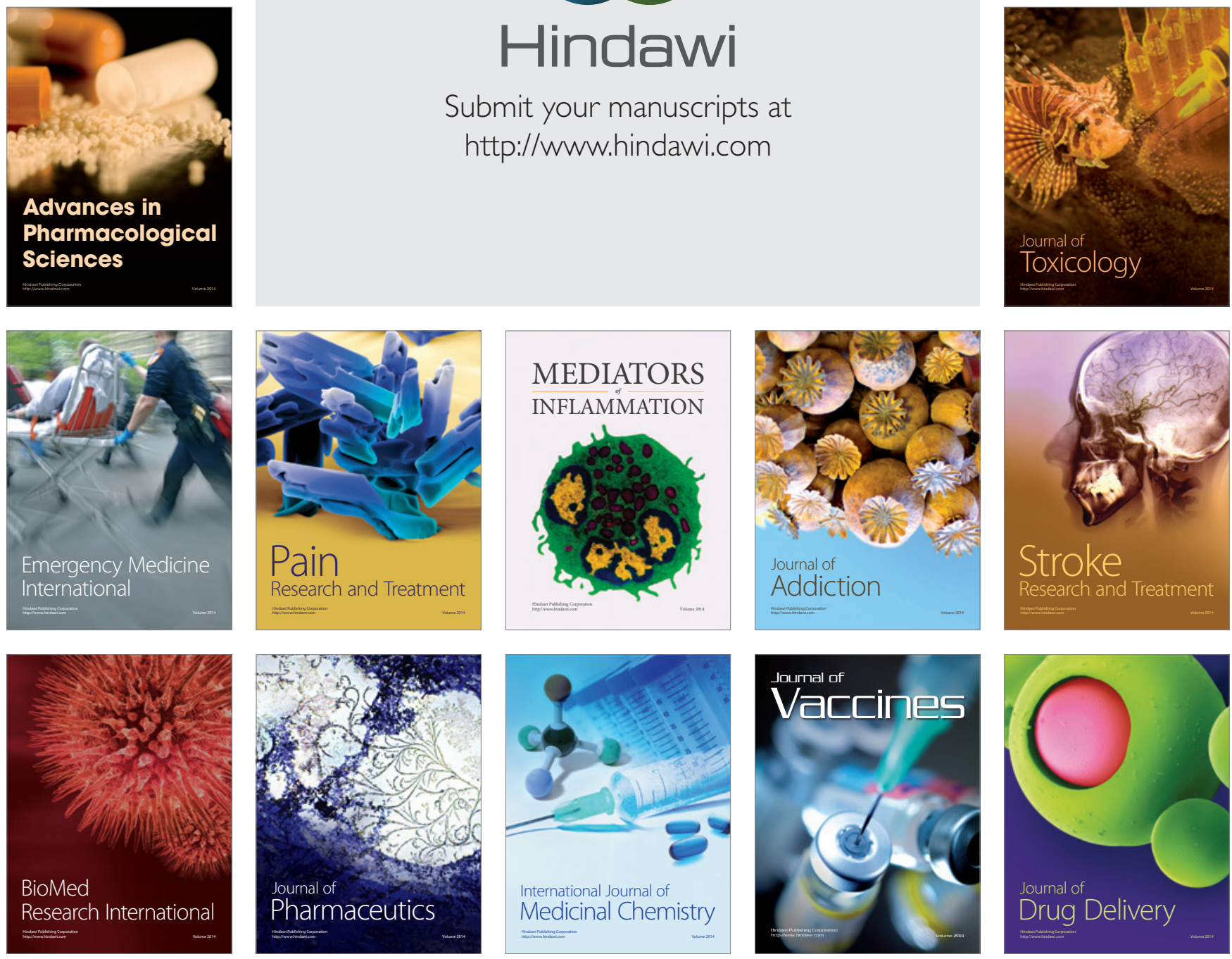